\title{
Assessment and analysis of writing ability of undergraduate students
}

\section{Veena Bhalerao, Vishala Patnam and Snehali Madrap}

Received: 27.01.2018; Revised: 02.10.2018; Accepted: 16.10 .2018

See end of the paper for authors' affiliations Veena Bhalerao Department of Human Development and Studies, College of Community Science, Vasantrao Naik Marathwada Krishi

Vidyapeeth, Parbhani (M.S.) India
ABSTRACT : Three hundred UG students were chosen at random from randomly selected 5 Colleges of Parbhani town. For this study purpose, a passage of 12 lines containing 155 words was chosen and individual students were given the printed passage to copy it down while seeing it, in small groups of $10 \mathrm{UG}$ students each, within given time and without time limit. The data related to study was collected from the UG students through structured cum open ended questionnaire, SES scale, by administering IQ test, GQ assessment and non-participatory observation technique. For the analysis of writing ability, the parameters considered were number of words, positioning of letters, placement of words, spacing between words, shape and appearance of the words from the given written passage and were rated on the five point scale i.e. Excellent, Very good, Good, Fair and Poor through the subjective evaluation.

KEY WORDS: Writing ability, Under graduate students, Educational background

- HOW TO CITE THIS PAPER : Bhalerao, Veena, Patnam, Vishala and Madrap, Snehali (2018). Assessment and analysis of writing ability of undergraduate students. Asian J. Home Sci., 13 (2) : 459-465, DOI: 10.15740/HAS/AJHS/13.2/459-465. Copyright@ 2018: Hind Agri-Horticultural Society. 